\title{
Literatura e identidade nacional em Angola
}

\author{
João Paulo Henrique Pinto \\ joaopaulohenriquepinto@gmail.com \\ Doutorando em História pela Universidade Federal do Rio de Janeiro, bolsista CAPES
}

\begin{abstract}
Resumo: O surgimento do nacionalismo angolano esteve diretamente ligado ao Movimento dos Novos Intelectuais de Angola. Estes intelectuais assumiram o papel de valorização das culturas de Angola e, consequentemente, contribuíram para definir o que seria a identidade nacional angolana. Este artigo tem como objetivo principal analisar, em linhas gerais, as principais características do Movimento dos Novos Intelectuais de Angola e refletir sobre a definição da identidade nacional que foi construída a partir de suas criações artísticas.
\end{abstract}

Palavras-chave: Literatura; Nacionalismo; Angola.

\section{Literature and national identity in Angola}

Abstract: The appearence of angolan nacionalism was directly linked to the Movimento dos Novos Intelectuais de Angola (Movement of the New Intellectuals of Angola). These intellectuals assumed a role of cultural valorization of Angola and, therefore, contributed to define what would be the angolan national identity. This article has as its main objective to analyse, in general terms, the main characteristics of the Movimento dos Novos Intelectuais de Angola and reflect about the definition of national identity which was constructed from its artistic criations.

Keywords: Literature; Nationalism; Angola.

A história de nossa literatura é testemunho da geração de escritores que souberam, na sua época, dinamizar o processo de nossa libertação exprimindo os anseios profundos de nosso povo, particularmente o das camadas mais exploradas. A literatura angolana surge assim não como simples necessidade estética, mas como arma de combate pela afirmação do homem angolano. ${ }^{214}$

O trecho citado faz parte do documento de fundação da União dos Escritores Angolanos (UEA) e data de 1975. Destas breves palavras, destaca-se a ideia de que a literatura angolana surgiu do projeto de libertar Angola da dominação portuguesa. Por ser um documento escrito no auge do processo de independência angolana, deve-se relativizar esta

\footnotetext{
214 Documento de fundação da União dos Escritores Angolanos citado por Rita Chaves em O projeto literário angolano: a identidade a contrapelo. In: CHAVES, Rita. A Formação do Romance Angolano - entre intenções e gestos. São Paulo: FBLP, Via Atlântica, 1999. p. 70.
} 
ideia, já que não se pode separar estas palavras da emoção sentida pelos fundadores da União dos Escritores Angolanos ao verem o sonho da independência concretizado.

Contudo, mesmo levando em conta o peso das palavras e o momento histórico em que foram proferidas, é possível relacionar diretamente o impacto do surgimento da literatura angolana ao início da luta contra a dominação portuguesa. Portanto, se não foi um projeto considerado a priori pelos intelectuais angolanos, certamente a literatura teve papel decisivo na construção de uma identidade para a nação que se formava, como uma extensa historiografia já demonstrou.

Analisar a obra da primeira geração de literatos nacionalistas de Angola é, sem dúvida, uma oportunidade para pensar a construção da nação angolana. Para isso, contudo, é necessário que se faça uma breve reflexão teórica sobre o conceito de nação mobilizado pelas ciências sociais para dar conta da construção das identidades nacionais. Após esta reflexão, será possível iniciar a análise da literatura angolana que se empenhou em definir e construir uma nação angolana.

Estudar a nação é inclinar-se sobre a cultura do grupo - ou dos grupos - que se pretende conhecer. Em geral, a cultura é considerada pelos nacionalistas a base sobre a qual a nação deve se edificar, é o elemento que une os membros da nação em um só corpo político. Entretanto, o campo da cultura não é um espaço hermeticamente fechado aos conflitos, mas

uma espécie de teatro onde várias causas políticas e ideológicas se empenham mutuamente. Longe de ser um reino plácido de refinamento apolíneo, a cultura pode ser um campo de batalha onde as causas se expõem à luz do dia e lutam entre si. ${ }^{215}$

Um dos estudos de maior importância para se iniciar o debate sobre as nações é "Comunidades Imaginadas: reflexões sobre a origem e a difusão do nacionalismo",216 onde Benedict Anderson afirma ser a nação uma construção social e não a essência de um grupo que se estabelece e organiza em torno de um Estado e em um território definido. $\mathrm{O}$ autor afirma que as nações são comunidades políticas imaginadas, não somente no sentido da invenção, mas principalmente no sentido de haver uma correspondência desta construção na

\footnotetext{
${ }^{215}$ SAID, Edward. Cultura e Imperialismo. São Paulo: Companhia das Letras, 1995, p. 5.

216 ANDERSON, Benedict. Comunidades imaginadas: reflexões sobre a origem e a difusão do nacionalismo. São Paulo: Companhia das Letras, 2008.
} 
alma de seus membros, que projetam desejos e traçam objetivos para a comunidade. ${ }^{217} \mathrm{O}$ processo de imaginação da nação só pode ser compreendido, portanto, quando se atenta para a repercussão afetiva que estes discursos têm para a população, ou seja, deve-se compreender a construção da nação em termos de suposições, esperanças, necessidades, aspirações e interesses das pessoas comuns, mesmo que este seja um fenômeno construído essencialmente por figuras e organizações de destaque, como Estados, partidos, intelectuais e lideranças políticas, tal como afirma Eric Hobsbawm em Nações e Nacionalismos desde 1740 - programa, mito e realidade. ${ }^{218}$

A nação é uma comunidade, segundo Benedict Anderson, porque todos os seus membros partilham de um sentimento de companheirismo profundo e horizontal. É imaginada, pois nenhum de seus membros jamais terá contato com todos os demais membros da nação, apesar de todos eles serem capazes de se identificar com seus semelhantes. É imaginada como limitada, porque seus limites são claramente definidos e separados das demais nações através de fronteiras. Por fim, a nação é imaginada como soberana, pois este conceito foi criado em um momento em que a legitimidade dos reinos dinásticos era contestada pelas revoluções burguesas e pelo lluminismo, especialmente pelas ideias de soberania e liberdade. A partir desta definição, Benedict Anderson apresenta empírica e teoricamente como as nações são imaginadas, dando ênfase principal ao papel do capitalismo de imprensa e à vernacularização das línguas para a construção das nações modernas. ${ }^{219}$

Partindo da ideia de que a identidade se encontra em crise no período conhecido como pós-modernidade, ${ }^{220}$ Homi Bhabha defende que a nação abriga dentro de suas fronteiras muito mais do que uma identidade nacional homogênea como acredita Benedict Anderson, pois há múltiplas identidades convivendo dentro das fronteiras da nação, que é caracterizada pelo seu hibridismo cultural. Não há, pois, na identidade nacional, a fixidez, mas uma constante negociação entre estas múltiplas identidades que a compõem. Para Homi Bhabha, o discurso produzido pela identidade nacional é redutor por não dar conta de narrar a

\footnotetext{
217 SCHWARCZ, Lilia Moritz. "Imaginar é difícil (porém necessário)" (Apresentação). In: ANDERSON, op. cit., p. 10. 218 HOBSBAWM, Eric. Nações e nacionalismos desde 1740 - programa, mito e realidade. Rio de Janeiro: Nova Fronteira, 2011, p. 21.

${ }^{219}$ ANDERSON, op. cit., p. 32-34.

${ }^{220}$ HALL, Stuart. A identidade cultural na pós-modernidade. Rio de Janeiro: DP\&A, 2004.
} 
hibridização, a multiplicidade, a ambivalência e a dispersão que caracterizam a nação póscolonial. 221

Sendo assim, Frederick Cooper sugere que a identidade nacional pode aparecer como mais uma identidade imaginada pelos africanos, mas não tem força suficiente para suprimir as demais identidades e se tornar hegemônica. ${ }^{222}$ Então, quem analisa a identidade nacional deve compreender como as múltiplas identidades se relacionam, entrando em conflito, se sobrepondo, se complementando e negociando entre si. Homi Bhabha propõe que esta análise ocorra a partir dos interstícios e dos espaços intervalares entre estas identidades culturais, pois é na "emergência dos interstícios que as experiências intersubjetivas e coletivas de nação (nationness), o interesse comunitário ou o valor cultural são negociados." 223

Indo adiante com esta abordagem que toma a nação a partir do seu hibridismo, Prasenjit Duara afirma que a nação pode ser imaginada de múltiplas formas pelas identidades que a compõem, sendo que sua imaginação depende de quem, quando, onde e do porquê desta nação ser imaginada. Portanto, o autor sugere que o pesquisador aborde a questão da identidade nacional a partir de uma perspectiva relacional, isto é, a partir da relação que ela tem com as outras múltiplas identidades presentes no interior da nação. ${ }^{224}$

Portanto, baseado na ideia de que a nação é uma comunidade imaginada, pretendese, neste artigo, compreender quais foram os aspectos selecionados pelos "pais fundadores" da nação para compor a identidade nacional angolana. Contudo, vista a enorme multiplicidade de matrizes culturais em Angola, é necessário considerar que a imaginação de uma nação não dá conta de todas as identidades presentes no interior do território nacional.

Neste sentido, é importante ter em mente que a cultura, base da identidade nacional, abriga em seu interior grandes diferenças, sendo, portanto, um campo de conflitos onde diversas matrizes culturais entram em contato. Sendo assim, dentro de um mesmo sistema cultural, pode haver adequação, articulação, apropriação ou conflito, de maneira que tratar o

\footnotetext{
${ }^{221}$ BHABHA, Homi K. O local da cultura. Belo Horizonte: Editora da UFMG, 1998, p. 24.

${ }^{222}$ COOPER, Frederick. "Conflito e Conexão - repensando a história colonial da África". Anos 90, V. 15, № 27, Porto Alegre. 2008, p. 47.

223 BHABHA, op. cit., p. 20.

224 DUARA, Prasenjit. "Historicizing national Identity, or who imagines what and when". In: SUNE, Eleyand. Becoming National, Oxford, Oxford University Press, 1996, p. 150-177.
} 
campo cultural de forma monolítica e homogeneizada acaba reduzindo a complexidade da questão. 225

Sendo a cultura um campo de disputa onde várias matrizes culturais se relacionam, a construção da nação é necessariamente um discurso redutor que seleciona alguns aspectos culturais e descarta outros que não lhe convém. Portanto, a elaboração de uma imaginação nacional a partir da seleção dos elementos culturais que melhor se adequam à ideia de nação que está sendo elaborada deve ser estudada com cautela, sempre tendo em vista a arbitrariedade que a construção de uma identidade nacional traz consigo ao selecionar e excluir aspectos mais condizentes com seus projetos e entendimentos sobre o que é a nação. Desta forma, pode-se investigar quem, como, quando e o porquê desta imaginação nacional ser elaborada, construindo, então, uma abordagem complexa sobre a identidade nacional.

Como se sabe, o colonialismo português em Angola foi intensificado a partir do século XIX e, com isso, a influência cultural europeia pôde ser mais sentida na colônia, de maneira que a literatura foi considerada uma das principais expressões culturais da dominação europeia. Neste trabalho, interessa-nos abordar o papel da literatura nacionalista surgida no final dos anos 1940 para a construção de uma identidade nacional. Busca-se, portanto, compreender como o confronto cultural entre uma literatura adepta ao colonialismo e uma nova literatura contestatária em Angola impactaram na formação de um movimento cultural nacionalista que construiu um discurso identitário para os angolanos. Vale ressaltar que esta elaboração identitária seria base para os movimentos de libertação nacional e para o Estado angolano após a independência definirem a nacionalidade angolana.

Neste ambiente de intensificação do colonialismo português em Angola, vigorava nas colônias portuguesas uma literatura escrita, em sua maioria, por portugueses, que adotavam uma

perspectiva de exotismo, evasionismo, preconceito racial e reiteração colonial e colonialista, em que a visão de mundo, o foco narrativo e as personagens principais eram de brancos, colonos ou viajantes, e quando se integravam os negros, eram estes avaliados superficialmente, de modo exógeno, folclórico e etnocêntrico, sem profundidade cultural, psicológica, sentimental e intelectual. ${ }^{226}$

\footnotetext{
225 THOMPSON, Edward. Costumes em Comum. São Paulo: Companhia das Letras, 1998.

226 PIRES LARANJEIRA. Literaturas africanas de expressão portuguesa. Lisboa: Universidade Aberta, 1995, p. 26.
} 
Esta literatura colonial expressava, em suma, a exaltação da nação portuguesa, baseada em seu espírito desbravador e civilizador, de maneira que os povos das colônias eram considerados meros coadjuvantes no processo de criação artística e, por extensão, em todo o Império Português. O objetivo implícito nas obras coloniais, então, era promover o ideal de assimilação dos povos nativos para elevá-los à cultura metropolitana. Este objetivo teve grande penetração na literatura desempenhada por alguns escritores angolanos, como por exemplo nas obras de José da Silva Maia Ferreira, ${ }^{227}$ que expressou o ideal de união benéfica entre angolanos e portugueses através dos seguintes versos:

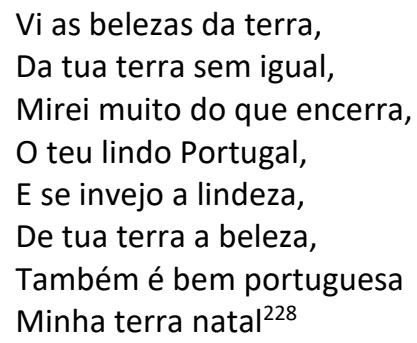

Este cânone da literatura colonial foi largamente difundido pela sociedade angolana através do Decreto-Lei 227085, que instituiu um currículo básico ao ensino nos liceus das colônias por onde os principais nomes da moderna literatura nacionalista angolana passaram durante o período de sua formação intelectual. ${ }^{229}$

Mesmo sendo muito marcadas pela literatura colonial, as obras de alguns autores de finais do século XIX e início do século XX deixavam transparecer alguns aspectos dissonantes das linhas gerais promovidas pelos escritores próximos àquela corrente literária. Este é o caso da obra de Assis Júnior ${ }^{230}$ intitulada 0 Segredo da Morta (romance de costumes

\footnotetext{
227 José Maria Maia Ferreira nasceu em 1827 em Luanda. Depois de morar no Brasil e nos EUA, Maia Ferreira fez carreira na administração pública de Angola. Dedicou-se também à literatura, sendo um importante representante da literatura colonial angolana. Seus biógrafos não sabem informar com precisão a data de seu falecimento.

228 FERREIRA, José Silva Maia. Espontaneidades da minha terra - às senhoras angolanas. Lisboa: Imprensa Nacional/ Casa da Moeda, 2002. Coleção Escritores dos Países de Língua Portuguesa, volume 30.

${ }^{229}$ KANDJIMBO, Luís; ANDRADE, Mário Pinto de; NETO, Agostinho. "A geração literária de 48 e o problema do slogan Vamos Descobrir Angola". In: MATA, Inocência; PADILHA, Laura (org.). Mário Pinto de Andrade - um intelectual na política. Lisboa: Edições Colibri, 1997, p. 60.

230 António de Assis Júnior nasceu em Golungo Alto em 1877. Ganhou destaque no campo literário, sendo a valorização dos costumes dos povos de Angola a principal marca de sua obra. É considerado o fundador do romance angolano, tendo publicado, entre outras obras, O Segredo da Morta-romance de costumes angolenses. Faleceu em Lisboa em 1960.
} 
angolenses), ${ }^{231}$ publicado em 1935, mas escrito vinte anos antes. Neste livro, é possível identificar uma atmosfera mais próxima daquilo que era entendido à época como angolense, mesmo que esta obra não tenha sido suficiente para superar definitivamente a literatura colonial. Considerado o fundador do romance angolano, O Segredo da Morta (romance de costumes angolenses) é a primeira obra no campo da ficção a analisar as relações culturais promovidas pelo colonialismo, marcada por uma dualidade cultural, onde conflitos, aproximações e sínteses têm espaço. Sendo assim, Assis Júnior valorizou o ambiente cultural da colônia ao relatar os costumes angolenses, ao abrir um espaço em sua escrita às marcas da oralidade e ao quimbundo, ${ }^{232}$ indo além do estilo proposto pela literatura colonial e inspirando uma série de escritores que viriam a criar um novo movimento literário em Angola.

Neste sentido, esta literatura que mesclava aspectos da literatura colonial com novas propostas estéticas - e até políticas - pode ser considerada uma manifestação cultural praticada nos interstícios deixados pelo colonialismo. ${ }^{233}$ Se não havia possibilidade de um rompimento total com a literatura colonial, tampouco se deixou de produzir uma literatura com tonalidades mais próximas à realidade vivida na colônia, mesmo que esta não fosse capaz de expressar ainda uma subversão total da ordem cultural vigente naquele momento.

Note-se que, ao promover uma literatura que abria espaço àquilo que se considerava ser os costumes angolenses, Assis Júnior selecionava os aspectos culturais que ele mesmo considerava legitimamente de Angola, certamente deixando de lado as múltiplas manifestações culturais dos diversos povos que habitavam a colônia.

Apesar das manifestações culturais dos filhos da terra em finais do século XIX e da existência de alguns autores que não se adequavam totalmente à lógica literária colonial, foi somente na década de 1940 que um movimento literário de maior envergadura deu os primeiros passos no sentido de formar uma literatura que eles mesmos consideravam de bases nacionais. Neste sentido, analisar o surgimento da moderna literatura nacionalista angolana é, além de uma empreitada pelo campo da cultura, um exercício de compreensão política, de maneira que não é possível pensar neste movimento somente a partir de suas

\footnotetext{
${ }^{231}$ ASSIS Jr., António. O Segredo da Morta - romance de costumes angolenses. 2a. Edição. Lisboa, Edições 70, 1979.

232 O interesse de António Assis Júnior pela relação estabelecida entre as culturas angolanas e portuguesa pode ser percebido em Gramática de quimbundo e português, publicado em 1941, demonstrando a sua preocupação em fazer entender também a língua predominante em Angola.

${ }^{233}$ Ver BHABHA, op. cit.
} 
bases estéticas sem englobar a dimensão política presente nas entrelinhas nos textos daqueles intelectuais. ${ }^{234}$

Esta geração de intelectuais angolanos que elaborou as bases da literatura nacionalista ironicamente esteve muito ligada ao ambiente acadêmico português, principalmente após a formação das casas de estudantes vindos das colônias portuguesas, como a Casa de Estudantes de Angola, a Casa dos Estudantes da Índia e de Cabo Verde e a Casa dos Estudantes de Moçambique. Desagradado com a divisão destas casas de estudantes segundo o critério de origem, o governo português uniu todas estas instituições na Casa dos Estudantes do Império (CEI) em 1944, com sedes em Lisboa, Coimbra e Porto. ${ }^{235}$ Ao fazê-lo, o governo português intentava fortalecer a mentalidade imperial e o sentimento de portugalidade entre os estudantes africanos residentes na metrópole. ${ }^{236}$ Além disso, controlar mais de perto as atividades destes estudantes também era uma necessidade, já que gradativamente a ideia de independência ganhava força entre os africanos.

A CEI, então, assumiu como sua atribuição prestar assistência social e material aos estudantes vindos das colônias, promover as suas culturas e integrá-los no meio estudantil metropolitano. Para isso, foram inaugurados postos de assistência médica, concedeu-se bolsas de estudos, organizou-se uma biblioteca e promoveu-se campeonatos de várias modalidades esportivas. ${ }^{237}$

Entretanto, o objetivo de controlar os estudantes e reforçar a mística imperial portuguesa fracassaram solenemente, já que a CEI deu lugar a importantes manifestações identitárias dos estudantes africanos. Aos poucos, iniciou-se uma intensa discussão sobre temas políticos, que logo levaria alguns dos associados à CEI a pensar nas possibilidades de independência das colônias. A importância desta associação foi de tal monta para o surgimento do nacionalismo nas colônias portuguesas que Mario Pinto de Andrade a apelidou de "berço das chefias africanas"238, pois naquela associação estiveram alguns dos principais

\footnotetext{
${ }^{234}$ CHAVES, op. cit.

235 PIMENTA, Fernando Manuel Tavares Martins. Brancos de Angola - autonomismo e nacionalismo (1900-1961). Coimbra: Edições Minerva, 2005, p. 138-139.

236 CASTELO, Cláudia. "A Casa dos Estudantes do Império: lugar de memória anticolonial". In Memories of Colonialism: rememberance, resistance and transference in anti-colonial african narratives. Disponível em <https://repositorio.iscte-iul.pt/handle/10071/2244 . . Acesso em 9 de agosto de 2016.

237 Ibidem, p. 7.

238 ANDRADE, Mario Pinto de. Apud MCQUEEN, Norrie. A descolonização da África Portuguesa - a revolução metropolitana e a dissolução do Império. Mem Martins: Inquérito, 1998, p. 38.
} 
líderes dos movimentos nacionalistas das colônias portuguesas, como Agostinho Neto, ${ }^{239}$ Marcelino dos Santos ${ }^{240}$ e Amílcar Cabral, ${ }^{241}$ entre outros nomes que posteriormente ganhariam grande destaque.

A CEI sempre se demonstrou muito arredia no que se referia à tutela salazarista, principalmente a partir da publicação do Boletim Mensagem ${ }^{242}$ iniciada em 1948 e finalizada somente em 1964. A publicação do Boletim Mensagem foi responsável por dar espaço às criações artísticas de uma geração de jovens intelectuais das colônias portuguesas que provavelmente não teriam este espaço de divulgação caso não estivessem radicados na metrópole e associados à Casa dos Estudantes do Império. Os canais de expressão política estavam fechados aos povos colonizados, de maneira que o único canal disponível para fazêlo era através do campo da cultura. Muito do pensamento anticolonial das colônias portuguesas foi gestado a partir das páginas daquele periódico, que pode, portanto, servir como importante fonte de análise do pensamento da geração que criou o nacionalismo literário angolano.

Além do Boletim Mensagem publicado pela CEI, a Revista Mensagem - a voz dos naturais de Angola também foi de extrema importância para a veiculação das ideias dos intelectuais nacionalistas angolanos. Publicada em Angola pela ANANGOLA, ${ }^{243}$ a Revista Mensagem revolucionou a literatura angolana, principalmente ao divulgar e propor novas

\footnotetext{
239 António Agostinho Neto nasceu em 1922. Durante sua juventude, residiu na Casa dos Estudantes do Império, período em que cursou medicina e se envolveu com a política. Na mesma época, participou de movimentos culturais africanos, tornando-se um renomado poeta. Foi fundador e presidente de honra do MPLA. Após a independência de Angola, tornou-se presidente da república. Faleceu em 1979.

240 Marcelino dos Santos nasceu em Moçambique em 1929. Atuou na articulação política para a libertação de Moçambique, sendo um dos fundadores da Frente de Libertação de Moçambique. Após a independência, ocupou os cargos de ministro da Planificação e Desenvolvimento e Presidente da Assembleia Popular de Moçambique. 241 Amílcar Cabral nasceu em 1924. Foi poeta, agrônomo e político, desempenhando importante papel na independência de Cabo Verde e Guiné-Bissau. Membro fundador do PAIGC, acabou sendo assassinado em 1973. 242 O nome destas publicações da CEI se confundem ao longo dos anos em que foram publicadas, podendo ser denominadas Mensagem, Boletim Mensagem ou somente Boletim. Apesar desta variedade de nomenclaturas, estas publicações seguem basicamente a mesma linha de divulgação e valorização da cultura das colônias portuguesas em África, tendo inclusive os mesmos colaboradores.

243 A ANANGOLA surgiu em 1947, sendo apenas uma nova nomenclatura assumida pelo Grêmio Africano, fundado em 1913. Inicialmente, a ANANGOLA tinha como associados, basicamente, mestiços e negros bem posicionados socialmente. Entretanto, na década de 1950, as bases desta associação foram expandidas através do ingresso de angolanos brancos e das ações voltadas às massas, como a criação de postos médicos e escolas de corte e costura e datilografia. A partir de então, associaram-se à ANANGOLA indivíduos das camadas mais baixas da sociedade. Ver BOSSLET, Juliana Cordeiro Farias. A Cidade e a Guerra - relações de poder e subversão em São Paulo de Assunção de Luanda. Dissertação de mestrado apresentada ao Programa de Pós-Graduação em História Social da Universidade Federal Fluminense. Niterói, 2014.
} 
ideias e padrões estéticos. Apesar de sofrer com a repressão do colonialismo e ter um pequeniníssimo número de publicações, ${ }^{244}$ a Revista Mensagem ainda é considerada um importantíssimo marco do surgimento do nacionalismo e de uma literatura angolana mais próxima das culturas africanas.

Após o surgimento do lema Vamos Descobrir Angola, ${ }^{245}$ muitos dos artistas e intelectuais que o compuseram se reagruparam em torno da designação Novos Intelectuais de Angola. ${ }^{246}$ Este movimento intelectual se agrupou em torno da Revista Mensagem - a voz dos Naturais de Angola. Esta designação do grupo fazia ainda referência à geração de literatos de finais do século XIX e início do XX que buscou dar importância aos valores e costumes considerados autenticamente próprios dos povos angolanos.

Nestas publicações dos Novos Intelectuais de Angola, é possível perceber que suas ideias e trabalhos deixam transparecer uma crítica ao domínio cultural imposto pelo colonialismo português, crítica esta que seria amplificada mais adiante também para o campo político. Pedro Sobrinho, por exemplo, em texto no Boletim Mensagem, considerou lamentável o estado em que a literatura angolana se encontrava em finais da década de 1940, principalmente devido à influência da literatura colonial. ${ }^{247}$ No mesmo texto, Pedro Sobrinho ainda destacou os principais expoentes literários que poderiam levar os artistas angolanos a

\footnotetext{
${ }^{244}$ A Revista Mensagem - a voz dos naturais de Angola teve apenas duas publicações, a primeira em julho de 1951 e a segunda em outubro de 1952. Após a divulgação destes números, a repressão se abateu sobre seus colaboradores. A partir de então, o grupo de intelectuais que levava a Revista Mensagem adiante se dispersou, mas o caráter político do movimento acentuou-se gradativamente, levando muitos daqueles intelectuais a se engajar na luta de libertação nacional. Ver ABDALA, Benjamin. "Panorama histórico da literatura angolana". In: CHAVES, Rita. MACÊDO, Tania. (orgs.) Marcas da Diferença - as literaturas africanas de língua portuguesa. São Paulo: Alameda, 2006.

245 Não há consenso sobre a paternidade do slogan Vamos Descobrir Angola. Segundo António Jacinto, esta palavra de ordem embasava todos os escritos daquela geração, sendo provável que "nenhum grupo de pessoas se sentou em uma mesa e disse: "Vamos Descobrir Angola". Ver LABAN, Michel. Angola - encontro com Escritores. Volume 1. Porto, Fundação Eng. António de Almeida, 1991, p. 146. Ver também SERRANO, Carlos. "Angola: a Geração dos 50, os jovens intelectuais e a raiz das coisas". Disponível no site da União dos Escritores Angolanos: <http://www.ueangola.com/criticas-e-ensaios/item/157-angola-a-gera\%C3\%A7\%C3\%A3o-de-50--os-jovensintelectuais-e-a-raiz-das-coisas>. Acesso em 22 de julho de 2015.

${ }^{246}$ Esta denominação faz uma referência comparativa entre esta nova geração de intelectuais da década de 1940 e os primeiros intelectuais que questionaram as ações portuguesas em Angola no final do século XIX e início do século XX, principalmente a partir da publicação da obra coletiva A Voz de Angola Clamando no Deserto. Apesar desta denominação, Pepetela afirma que pouquíssimos dos Novos Intelectuais de Angola conheciam as obras dos Velhos Intelectuais de Angola. Ver Pepetela. "Algumas questões sobre literatura angolana". Disponível em <http://www.ueangola.com/criticas-e-ensaios/item/122-algumas-quest\%C3\%B5es-sobre-a-literatura-angolana $\geq$ . Acesso em 26 de maio de 2015.

247 SOBRINHO, Pedro. "Panorama geral da literatura angolana". BOLETIM - Casa dos Estudantes do Império. Ano 1, número 6. Lisboa, Sem data. p. 16.
} 
um novo rumo, mais autêntico e afinado com as necessidades de sua terra. Ficam nítidas, então, algumas características básicas da publicação do Boletim Mensagem, que buscava

incitar os jovens estudantes de letras à análise atenciosa da obra já realizada por homens de boa vontade em todo o ultramar. A divulgação dos escritores ultramarinos, a descoberta de novos valores, a crítica, muito contribuirão [contribuiriam] para o progresso das letras no ultramar. ${ }^{248}$

Destaca-se, então, o objetivo do Boletim Mensagem de criar e divulgar novos valores para a edificação de literaturas mais próximas à realidade das colônias portuguesas.

Já a edição da Revista Mensagem - a voz dos naturais de Angola publicada pela ANANGOLA, trouxe em seu número inicial uma proposta mais explícita acerca da construção e divulgação de uma cultura angolana, afirmando ser

necessário revelar valores ignorados, impondo-os; corrigir hábitos mentais defeituosos; definir posições e conceituar a verdadeira Cultura Angolana, livre de todos os agentes decadentes e dirigir a opinião pública para uma corrente sã e estruturalmente valorosa, que quer, pode e há-de impor-se. ${ }^{249}$

Neste ponto, é importante refletir sobre o que estes intelectuais consideravam a "verdadeira Cultura Angolana", uma vez que no interior da colônia existiam diversos povos e matrizes culturais. Cabe adiantar que, como será apresentado mais à frente, estes intelectuais selecionaram aspectos culturais que mais se adequavam ao seu entendimento do que seria uma cultura legítima de Angola, seleção esta que tinha muito a ver com as projeções para a construção de uma nação independente.

Entretanto, para que se construísse esta nova cultura angolana, seria necessário combater o cânone colonial a que os povos angolanos vinham sendo submetidos pelo governo português, como pode ser visto na denúncia feita por Agostinho Neto:

Os nativos são educados como se tivessem nascido e residissem na Europa. Antes de atingirem a idade em que são capazes de pensar sem esteio, não conhecem Angola. Olham a sua terra de fora para dentro e não ao invés, como seria óbvio. Estudam na

\footnotetext{
248 SOBRINHO, Pedro. "Panorama geral da literatura angolana". BOLETIM - Casa dos Estudantes do Império. Ano 1, número 6. Lisboa, Sem data, p. 18.

249 DEPARTAMENTO CULTURAL. "O nosso programa". Revista Mensagem - a voz dos naturais de Angola. Luanda: ANANGOLA, Ano 1, julho de 1951, no1. p. 2.
} 
escola, minuciosamente a História e a geografia de Portugal, enquanto que as da Colónia apenas folheiam em sinopses ou estudam muito levemente. Ingenuamente, suspiram pelas regiões temperadas do norte, por onde lhes arda o coração. Não compreendem esta gente que aqui havia, os seus costumes e idiossincrasia. Não têm tradições. Não têm orgulho de sua terra porque nela nada encontram de que se orgulhar; porque não a conhecem. Não têm literatura, têm a alheia. Não têm arte sua. Não têm espírito.

Não adoptam uma cultura; adaptam-se a uma cultura.

Os indivíduos assim formados têm a cabeça sobre vértebras estranhas, de modo que as ideias, as expirações do espírito são estranhas à terra. Daí o olhar-se esta, a sua gente e hábitos, o mundo que os rodeia, como estranhos a si - de fora. ${ }^{250}$

Portanto, os intelectuais desta geração tinham dois propósitos principais: (1) romper com o domínio cultural imposto pela metrópole às colônias, principalmente no campo literário, o que mais tarde desencadearia também uma luta política contra o colonialismo; e (2) construir uma identidade cultural própria de Angola, elaborando, mesmo que sem consciência disso, uma imaginação para a nação que ganharia corpo nas décadas seguintes durante a luta de libertação e também no período pós-independência.

A construção desta literatura mais combativa e propositiva de bases nacionais teria força, em Angola, principalmente através da poesia, sendo que o romance ganharia mais fôlego somente a partir da década de 1950. A prosa feita até então era muito marcada ainda pelas características da literatura colonial, onde os angolanos eram vistos como parte de um mundo exótico africano, não merecendo, portanto, nenhum protagonismo na literatura. Segundo Rita Chaves, esta falta de uma análise mais profunda e complexa sobre os povos naturais de Angola e de suas tradições culturais era um reflexo da falta de protagonismo dos próprios angolanos em sua história. ${ }^{251}$

Neste contexto de ebulição cultural em Angola, a seleção de valores e conceitos deve ser entendida, então, como uma construção que visava definir uma identidade própria de Angola. Em grande medida sob a liderança de Viriato da $\mathrm{Cruz}^{252}$ um dos mais influentes poetas

\footnotetext{
${ }^{250}$ Agostinho Neto citado por Luís Kandjimbo em Mário Pinto de Andrade, Agostinho Neto, a geração literária de 48 e o problema do slogan Vamos Descobrir Angola. In: MATA, Inocência; PADILHA, Laura (organizadoras). Mário Pinto de Andrade - um intelectual na política. Lisboa: Edições Colibri, 1997. p. 60

${ }^{251}$ CHAVES, Rita. O projeto literário angolano: a identidade a contrapelo. In: CHAVES, Rita. Angola e Moçambique - experiência colonial e territórios literários. Cotia, SP: Ateliê Editorial, 2005. p.73.

252 Viriato Francisco Clemente da Cruz nasceu em 1928. Teve destacada atuação no campo cultural, sendo um dos grandes impulsionadores da moderna literatura angolana. Engajou-se nas questões pela libertação de Angola e foi um dos fundadores do MPLA, do qual foi secretário-geral até 1962, ano em que se desligou definitivamente da organização devido a uma crise interna do movimento. Em 1966, mudou-se para Pequim, onde continuou a desenvolver atividades culturais e políticas. Faleceu em 1973.
} 
desta geração de intelectuais, ${ }^{253}$ a literatura nacionalista pode ser caracterizada por alguns aspectos comuns a todas as obras daquela geração.

Apesar da valorização de um patrimônio cultural considerado legitimamente angolano ser muito cara àquela geração literária, foi através da língua portuguesa que o movimento dos Novos Intelectuais de Angola se manifestou, sendo poucos os artistas que utilizaram as línguas faladas em Angola nas suas obras.

Entretanto, uma constante entre os intelectuais que compunham o movimento era a valorização das línguas faladas no território angolano, principalmente do quimbundo, como pode ser observado nas palavras de Agostinho Neto, que denunciou a pouca importância dada aos elementos das culturas próprias dos povos angolanos, apontando este aspecto como uma das causas de a cultura portuguesa ser tão poderosa em Angola:

quando nossas línguas, aquelas que serviram e servem de veículo à cultura angolana, não são faladas nas escolas, não são usadas nos jornais, na rádio, etc. (...) é evidente que a nossa cultura não se pode desenvolver. Estaciona; degrada-se, mas felizmente não morre. ${ }^{254}$

Sendo assim, a valorização das línguas faladas em Angola seria manifestada principalmente através da apropriação da língua do colonizador pelo movimento dos Novos Intelectuais de Angola. ${ }^{255}$ Portanto, apesar de usar o português como base, aqueles artistas se empenharam em criar uma diç̧ão própria dos angolanos, marcada por traços de oralidade, pela subversão sintática e léxica da norma culta e pela utilização de palavras e expressões em

\footnotetext{
253 Após o rompimento com o MPLA decorrente da crise interna do movimento ocorrida entre 1962-1964, Viriato da Cruz foi relegado a um segundo plano do movimento Vamos Descobrir Angola. Contudo, a historiografia vem ressaltando o seu protagonismo e sua importância à geração que fundou a moderna literatura angolana. Ver Fernando Mourão. Prefácio. In: ROCHA, Edmundo; SOARES, Francisco; FERNANDES, Moisés (orgs). Viriato da Cruz - o homem e o mito - Porto Amboim (Angola), 1928 - Beijing (China) 1973. Luanda: Caxinde, 2008.

254 NETO, Agostinho. "Introdução a um colóquio sobre poesia negra”. Mensagem. Casa dos Estudantes do Império, Ano III, números 5 e 6. Sem data. p.45.

${ }^{255}$ Apesar de poucas, houve exceções à utilização da língua portuguesa pelos Novos Intelectuais de Angola, como pode ser visto nos poemas de Mário Pinto de Andrade Muimbu ua Sabalu (Canção de Sabalu). Boletim - Casa dos Estudantes do Império, ano II, número 8. Sem data. p.17. Entretanto, mesmo publicado o original em quimbundo, na página seguinte há a tradução do poema para o português, o que reafirma a opção nítida pela divulgação das obras e ideias daqueles intelectuais através da língua metropolitana.
} 
quimbundo salpicadas em textos escritos em português, ${ }^{256}$ como pode ser percebido no poema Castigo p'ro Comboio Malandro, de António Jacinto ${ }^{257}$ :

\author{
Esse comboio malandro passa \\ Passa \\ Passa sempre com a força dele \\ Ué ué ué \\ Hi hi hi \\ Te-quem-tem te-quem-tem te-quem-tem \\ O comboio malandro \\ Passa \\ Nas janelas muita gente: \\ Ai bô viaje \\ Adeujo homé \\ Nganas bonitas \\ Quitandeiras de lenço encarnado \\ Levam cana no Luanda p'ra vender \\ Tem outro \\ Igual como este dos bois \\ Leva gente, muita gente como eu \\ Cheio de poeira \\ Gente triste como os bois \\ Gente que vai no contrato \\ Tem bois que morre no viagem \\ Mas o preto não morre \\ Canta como criança: \\ Mulondo iá Quéssua uádibalé \\ Uádibalé uádibalé uádibalé (...) ${ }^{258}$
}

O interesse pelo quimbundo promovido pelos Novos Intelectuais de Angola também teve como fruto a elaboração, por Mário Pinto de Andrade, ${ }^{259}$ de pesquisas sobre a linguística banto, que, mesmo sendo extremamente densas e de elevada erudição, foram publicadas nos

\footnotetext{
${ }^{256}$ CHAVES, op. cit., p. 72.

257 António Jacinto nasceu em 1924 e foi um dos mais destacados poetas da poesia angolana. Ao lado de Viriato da Cruz fundou as bases da moderna literatura nacionalista angolana a partir da década de 1940. Fundador do efêmero Partido Comunista Angolano, acabou se juntando ao MPLA e colaborando na luta de libertação nacional de Angola. Esteve preso no Tarrafal entre 1962 e 1972 por promover atividades anticolonialistas. Após a independência, foi ministro da Cultura de Angola e membro do Comitê Central do MPLA. Faleceu em 1991.

${ }^{258}$ António Jacinto. Castigo p'ro Comboio Malandro. Publicado em MENSAGEM, ano III, números 3 e 4, Boletim da Casa dos Estudantes do Império, Lisboa, 1960. p.25-26

259 Mario Pinto de Andrade nasceu em 1928. Foi um dos fundadores do MPLA e desenvolveu uma relevante obra sociológica sobre a cultura angolana, sendo um dos principais intelectuais a pensar novas formas de se construir uma identidade autenticamente angolana. Exerceu o cargo de presidente do MPLA. Faleceu em 1990.
} 
números da Revista Mensagem - a voz dos naturais de Angola ${ }^{260}$ A publicação destes estudos é emblemática, pois, mesmo sendo um texto complexo e de caráter muito específico, a Revista Mensagem - a voz dos naturais de Angola incluiu estes artigos em seus números, principalmente para marcar uma posição sobre a importância dada ao patrimônio linguístico próprio de Angola, sinalizando à necessidade de se compreender aquilo que era considerado legitimamente angolano.

No mesmo sentido da valorização das línguas angolanas, o movimento dos Novos Intelectuais de Angola se esmerou em conhecer profundamente as tradições culturais dos povos que ali habitavam. A palavra de ordem Vamos Descobrir Angola não ficou limitada somente ao campo das intenções, de maneira que os intelectuais de fato imergiram nas múltiplas culturas presentes na colônia. Sendo assim, o folclore e as tradições angolanas foram sempre muito valorizados por esta geração que fundou a moderna literatura angolana. ${ }^{261}$

Esta característica pode ser evidenciada em artigo de Fernando Mourão, publicado no Boletim Mensagem, onde o autor relata o deboche dos povos africanos ao ouvirem as fábulas de Esopo por não se identificarem com os elementos presentes nestas narrativas. ${ }^{262}$ É emblemática também a divulgação de exposições sobre o folclore tradicional angolano na Revista Mensagem, a voz dos naturais de Angola, demonstrando o ambiente de valorização das tradições angolanas, o que também pode ser visto no texto em que Fernando Mourão

\footnotetext{
${ }^{260}$ Chama a atenção o caráter acadêmico dos textos, com citações em inglês, discussões teóricas e grande complexidade. Ver ANDRADE, Mário Pinto de. "Questões de Linguística Banto". Revista Mensagem - a voz dos naturais de Angola. Edição do Departamento Cultural da Associação dos Naturais de Angola, Luanda, julho de 1951, número 1. p. 6.

261 A valorização do folclore angolano pode ser percebida pela publicação de notas e divulgação de exposições sobre estas manifestações culturais tradicionais. Ver, por exemplo, nota sobre a apresentação do Grupo Folclórico de Luanda no Rádio Clube. Ver "Panorama". Revista Mensagem - a voz dos naturais de Angola. Edição do Departamento Cultural da Associação dos Naturais de Angola. Luanda, julho de 1951, número 1. p.9. É possível notar também a importância dada ao folclore angolano no artigo de CÂMARA, Lúcio. "Contribuição para o Folclore Angolano". Mensagem - Boletim da Casa dos Estudantes do Império, ano XIV, número 4. Sem data. p. 22-27

262 MOURÃO, Fernando. "Breve apontamento sobre a "Viragem" de Castro Soromenho". Mensagem - Boletim da Casa dos Estudantes do Império, ano III, número III, sem data, p. 6-9.
} 
enaltece a obra de Castro Soromenho, ${ }^{263}$ autor que se aprofundou nas lendas e no folclore dos povos angolanos para dar bases consideradas nacionais para sua obra. ${ }^{264}$

A valorização dos aspectos tradicionais das culturas consideradas legitimamente angolanas também foi muito trabalhada nas poesias de Viriato da Cruz, que, além da valorização da oralidade e da diç̧ão própria angolana, evidenciava a necessidade de se tirar força das tradições da terra para que a vida de seus povos pudesse prosperar e se fortalecer. É essa a mensagem que se vê em Makèzú:

\author{
Kuakié!... Makèzú... \\ O pregão da avó Ximinha \\ É mesmo como os seus panos \\ Já não tem a cor berrante \\ Que tinha nos outros anos. \\ Avó Xima está velhinha \\ Mas de manhã, manhãzinha, \\ Pede licença ao reumático \\ E num passo nada prático \\ Rasga estradinhas na areia... \\ Lá vai para um cajueiro \\ Que se levanta altaneiro \\ No cruzeiro dos caminhos \\ Das gentes que vão p'ra Baixa. \\ Nem criados, nem pedreiros \\ Nem alegres lavadeiras \\ Dessa nova geração \\ Das "venidas de alcatrão" \\ Ouvem o fraco pregão \\ Da velhinha quitandeira. \\ - Kuakié!... Makèzú, Makèzú... \\ - Antão, véia, hoje nada? \\ - Nada, mano Filisberto... \\ Hoje os tempo tá mudado... \\ - Mas tá passá gente perto... \\ Como é aqui tá fazendo isso?
}

\footnotetext{
${ }^{263}$ Fernando Monteiro de Castro Soromenho nasceu em Chinde, Moçambique, em 1910. Com apenas um ano de idade, mudou-se com sua família para Angola. Na sua juventude, estudou em Lisboa e, após concluir seus estudos, regressou a Angola, onde desempenhou, entre outras, as profissões de jornalista e literato. Seu trabalho literário é marcado pela análise profunda das culturas angolanas. Após lecionar em universidades europeias, Castro Soromenho se transferiu para São Paulo, onde contribuiu para a fundação do Centro de Estudos Africanos da Universidade de São Paulo. Faleceu em São Paulo em 1968.

264 Ver SOROMENHO, Castro. Terra Morta. Luanda: União dos Escritores Angolanos, 1985. SOROMENHO, Castro. Viragem. São Paulo: Arquimedes, 1967. Foi nestas duas obras que o autor desenvolveu romance sociológico angolano.
} 


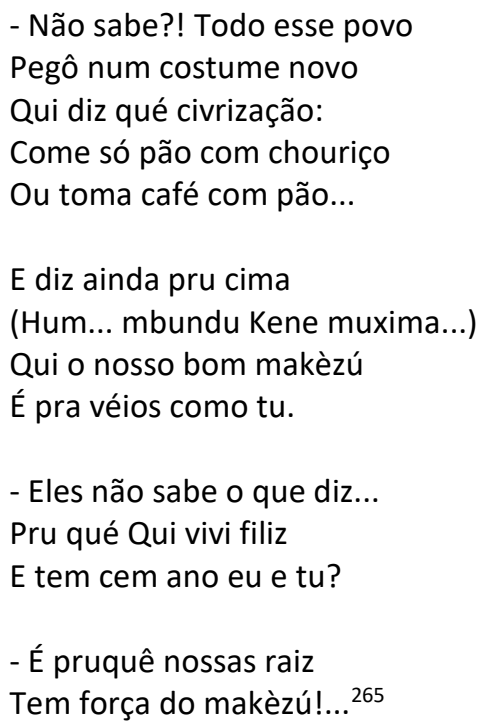

Neste poema, Viriato da Cruz buscou inserir o leitor no ambiente retratado, fornecendo elementos bastante vivos para que este objetivo fosse alcançado, como a fala dos personagens muito marcada pela oralidade e a própria caracterização do ambiente. A utilização do quimbundo nas falas dos personagens contrasta com a norma culta utilizada pelo narrador, configurando um estilo de escrita típico da geração dos Novos Intelectuais de Angola, onde o moderno (português) se mistura a elementos tradicionais, no caso o quimbundo, sem a ele se sobrepor. A conclusão de que a "civrização" acaba com as raízes e com a vida tradicional (representada pelo makèzú ${ }^{266}$ ) é um símbolo bastante forte e um estímulo à resistência ao colonialismo.

A valorização das tradições e culturas angolanas defendida pelos Novos Intelectuais de Angola também foi expressa através da idealização de um passado anterior à presença dos portugueses em território angolano. ${ }^{267}$ Sendo assim, certamente houve a construção e a expressão de uma memória coletiva que positivava uma experiência mais autônoma dos angolanos, demonstrando sutilmente a predisposição a um confronto com a estrutura colonial.

Entende-se aqui a memória como uma construção elaborada em função do presente, onde alguns eventos são lembrados e outros deliberadamente esquecidos em função dos

\footnotetext{
${ }^{265}$ CRUZ, Viriato. "Makèzú". In: ROCHA; SOARES; FERNANDES (orgs), op. cit., p. 53.

266 O makèzú (noz de cola) é utilizado por muitos povos africanos como primeiro alimento comido no dia, antes mesmo da primeira refeição mais substancial. O makèzú também é um símbolo utilizado em diversas cerimônias sociais, como em funerais, festejos, casamentos, nascimentos etc.

267 CHAVES, op. cit., p. 50.
} 
interesses imediatos daqueles que a constroem. É importante frisar que a construção de uma memória geralmente acaba suplantando as memórias subterrâneas, isto é, aquelas que não estão em acordo com a memória dominante. ${ }^{268}$ Desta forma, ao elaborar-se um discurso dominante sobre as experiências do passado, cria-se verdades absolutas e mitos incontestáveis, que devem ser identificadas com a totalidade nacional ao mesmo tempo em que silencia e esquece os eventos históricos que seriam problemáticos ao presente e às intenções de quem constrói a memória.

Neste sentido, os Novos Intelectuais de Angola construíram e manifestaram, então, uma memória que idealizava um passado, apresentando-o como um período em que as riquezas e os valores culturais angolanos não teriam sido apagados pela influência do colonialismo português. Com os olhos no presente, portanto, esta memória expressava a necessidade de dar importância àquilo considerado autenticamente angolano, tecendo, então, uma crítica ácida sobre tudo o que seria próprio da cultura portuguesa levada a Angola a partir do colonialismo.

Muitas vezes, a idealização do passado era expressa através dos temas relativos à infância, onde os poemas e livros relacionavam a juventude ao tempo de liberdade e de realizações. António Jacinto, em $O$ Grande Desafio, por exemplo, faz comparações entre duas épocas distintas.

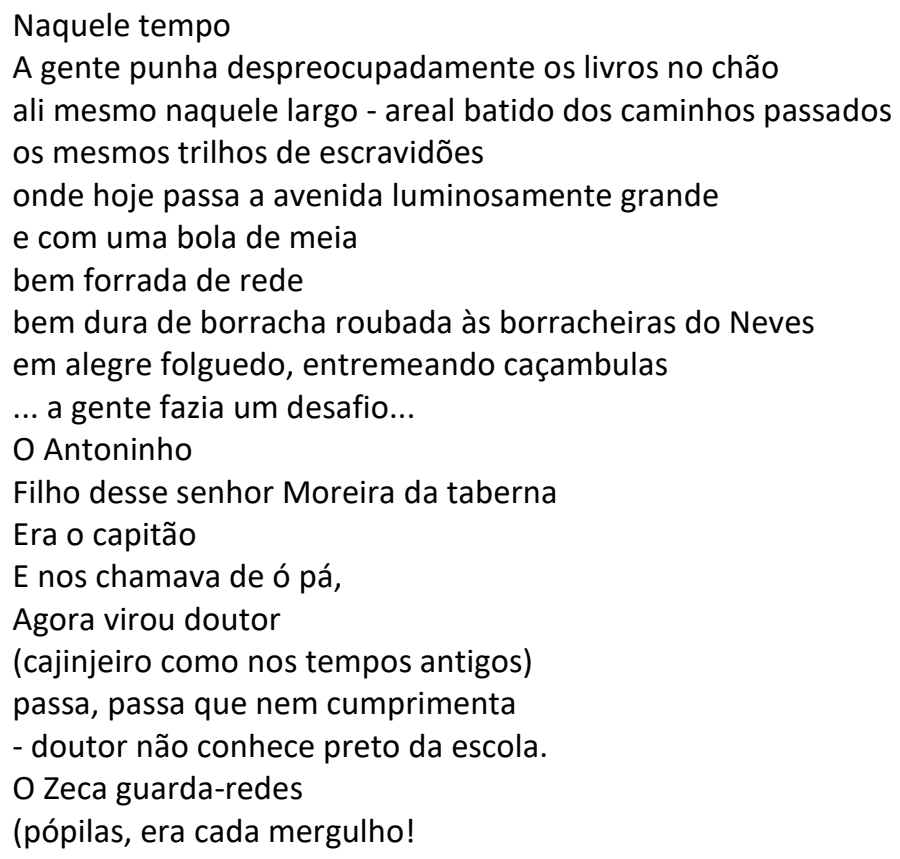

268 POLLAK, Michel. Memória, Esquecimento, Silêncio. In: Estudos Históricos. Rio de Janeiro, volume 2, número 3, 1989. p. 3-15. 
Aí rapage - gritava em delírio a garotada)

Hoje joga num clube da Baixa

Já foi a Moçambique e no Congo

Dizem que ele vai ir em Lisboa

Já não vem no Musseque

Esqueceu mesmo a tia Chiminha que lhe criou de pequenino

nunca mais voltou nos bailes de Don'Ana, nunca mais

Vai no Sportingue, no Restauração

outras vezes no choupal

que tem quitatas brancas

Mas eu lembro sempre o Zeca pequenino

O nosso saudoso guarda-redes!

Tinha também

tinha também o Velhinho, o Mascote, O Kamauindo...

- Coitado do Kamauindo!

Anda lá na casa da Reclusão

(desesperado deu com duas chapadas na cara

do senhor chefe

naquele dia em que lhe prendeu e lhe disparatou a mãe);

- O Velhinho vive com a Ingrata

drama de todos os dias

A Ingrata vai nos brancos receber dinheiro

E traz pro Velhinho beber;

- E o Mascote? Que é feito do Mascote?

- Ouvi dizer que foi lá em S. Tomé como contratado.

É verdade, e o Zé?

Que é feito, que é feito?

Aquele rapaz tinha cada finta!

Hum... deixa só!

Quando ele pegava com a bola ninguém lhe agarrava

vertiginosamente até na baliza.

E o Venâncio? O meio-homem pequenino

que roubava mangas e os lápis nas carteiras?

Fraquito da fome constante

quando apanhava um pinhão chorava logo!

Agora parece que anda lixado

Lixado com doença no peito.

Nunca mais! Nunca mais!

Tempo da minha descuidada meninice, nunca mais!...

Era bom aquele tempo

era boa a vida a fugir da escola a trepar aos cajueiros

a roubar os doceiros e as quitandeiras

às caçambulas:

Atresa! Ninguém! Ninguém!

tinha sabor emocionante de aventura

as fugas aos polícias

às velhas dos quintais que pulávamos $(\ldots)^{269}$

269 JACINTO, António. O Grande Desafio. Disponível em: <http://www.portalsaofrancisco.com.br/alfa/antoniojacinto/poesias.php>. Acessado em 16 de junho de 2015. 
Na fase da infância, o poema relata os hábitos das crianças negras, mestiças e brancas através de uma rica descrição de suas brincadeiras (jogos de futebol, no caso), a partir das quais se mantinha uma relação de fraternidade e igualdade. Entretanto, apesar deste passado de experiências tão ricas, no segundo momento analisado na poesia, a juventude se vai e os amigos de outrora se distanciam em função dos caminhos que seguiram e dos limites raciais e econômicos que a sociedade colonial comportava.

Antoninho, o único branco do grupo de amigos, tornou-se doutor e fazia questão de não se relacionar com os amigos da infância, já que "não conhecia preto da escola". Zeca também tinha pouco contato com os amigos da infância, pois se tornou jogador de futebol e só frequentava lugares onde se poderia encontrar prostitutas ${ }^{270}$ brancas, hábito considerado símbolo de distinção social. Este caso do personagem Zeca é interessante na medida em que mostra que uma das poucas possibilidades de ascensão social dadas aos negros era por meio do esporte e, além disso, mostra a predominância de um padrão de beleza congruente às características físicas dos europeus, marcada principalmente pela cor da pele. Os negros que não tinham a sorte de se colocar no ambiente futebolístico eram submetidos ao domínio colonial, como pode ser visto pelas histórias de Kamauindo, preso na casa de Reclusão após esbofetear seu chefe, Velhinho, que dependia do dinheiro conseguido através dos brancos, e Mascote, recolhido pelo trabalho por contrato em São Tomé. ${ }^{271}$

Há, portanto, uma clara positivação do passado, entendido como período de liberdade e igualdade, no qual provavelmente a infância implicava uma dose menor de colonialismo, de exploração e de imposição cultural. Ao mesmo tempo, António Jacinto fazia uma dura crítica ao momento vivido em Angola na época da publicação da poesia, simbolizada pelo abandono dos valores perdidos na infância.

\footnotetext{
270 Em Angola, quitata significa prostituta.

${ }^{271}$ A legislação trabalhista portuguesa para as colônias africanas determinava a necessidade dos nativos pagarem o Imposto Indígena. Contudo, como nem sempre os nativos estavam inseridos em uma situação de mercado e eram muitas vezes mais ligados à forma de trabalho tradicional sem moeda, o colonialismo português se esforçou para que o pagamento do referido imposto se tornasse realidade. Para tanto, instituiu-se o trabalho por contrato, espécie de trabalho forçado em que os habitantes das colônias eram inseridos no mercado de trabalho formal através da venda de sua força de trabalho em troca de pagamento em moeda. Assim, os chamados indígenas, com o rendimento do trabalho por contrato, poderiam arcar com os custos do Imposto Indígena. Neste sistema de trabalho por contrato, as forças colonialistas detinham os indivíduos que não eram ligados a um posto de trabalho no mercado formal e os enviavam para campos de trabalho de acordo com as necessidades das autoridades coloniais.
} 
Neste mesmo sentido de valorização da resistência ao colonialismo e das tradições consideradas autenticamente angolanas, o movimento dos Novos Intelectuais de Angola gradativamente se dedicou às análises do sistema colonial português, promovendo a denúncia dos problemas legados a Angola pela exploração da metrópole colonial. No poema Renúncia Impossível, de Agostinho Neto, é possível perceber uma crítica bastante contundente ao colonialismo e uma enunciação de um sentimento de revolta latente:

\author{
Não contem comigo \\ Para vos servir às refeições \\ Nem para cavar os diamantes \\ Que vossas mulheres irão ostentar em salões \\ Nem para cuidar das vossas plantações \\ De café e algodão \\ Não contem com operários \\ Para amamentar os vossos filhos sifilíticos \\ Não contem com operários \\ De segunda categoria \\ Para fazer o trabalho de que vos orgulhais \\ Nem com soldados inconscientes \\ para gritar com o estômago vazio \\ vivas ao nosso trabalho de civilização \\ nem com lacaios \\ para vos tirarem os sapatos \\ de madrugada \\ quando regressardes de orgias nocturnas \\ nem com pretos medrosos \\ para vos oferecer vacas \\ e vender molho a tostão \\ nem com corpos de mulheres \\ para vos alimentar de prazeres \\ nos ócios da vossa abundância imoral. ${ }^{272}$
}

A partir da recusa à submissão ao poder colonial e aos colonos, Agostinho Neto unia diretamente na poesia as causas políticas às causas culturais pelas quais militava. Assim como diversos outros artistas de sua geração, Agostinho Neto defendia a liberdade e a soberania perdidas no momento da imposição do colonialismo português, arriscando-se assim em uma luta pela independência. Portanto, criar uma estética própria de Angola passava a significar também criar politicamente uma nova Angola, livre da dominação, dos problemas sociais, políticos econômicos e culturais decorrentes do colonialismo português.

\footnotetext{
272 NETO, Agostinho. Renúncia impossível. 1949. Disponível em http://www.agostinhoneto.org/index.php?option=com content\&view=article\&id=537:a-renuncia impossivel\&catid=65: renuncia-impossível\&Itemid =233. Acesso em 2 de junho de 2015.
} 
Apesar da denúncia das estruturas colonialistas e do gradual empenho na defesa da libertação nacional, estes intelectuais e artistas viam na exploração a que o colonialismo submeteu os angolanos um traço de identificação dos povos ali residentes. ${ }^{273}$ Portanto, a imaginação da identidade nacional angolana partia também da História dos povos que compunham a nação, como pode ser visto em Poema de Mário António Fernandes de Oliveira, considerado o melhor poeta do biênio 1951-1952 pelo concurso promovido pela Revista Mensagem, a voz dos naturais de Angola:

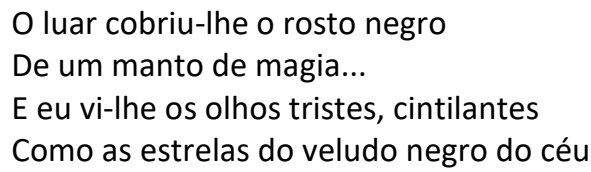

Apertei em meus braços.

Seu corpo virgem, escaldante...

- e ela fugiu, veloz, aos meus abraços...

Os seus olhos tinham uma expressão parada,

E eu que se fixavam no passado,

No passado misterioso e insondável...

Seus olhos perscrutavam um mistério

E os meus, os meus olhos febricitantes, Mergulharam no mistério dos seus olhos.

E vi...

E vi filas de escravos no sertão,

E vi negros chorando no porão

Do negreiro.

E ouvi...

E ouvi o ruído das correntes

E o grito das mães sem filho

E das amadas sem noivo.

E os meus lábios se abriram, temerosos,

Para contar a grande história,

A história triste...

E contei

Ela não disse nada.

Os seus olhos tinham a mesma expressão [parada

O mesmo gelo na quietude do seu rosto.

Então

${ }^{273}$ MOURÃO, Fernando. "Antologia da poesia negra de expressão portuguesa, por Mário de Andrade". Mensagem - Boletim da Casa dos Estudantes do Império. Ano III, número 1. Sem data. p. 9-10. 
Vi que ela tudo sabia

Eque

o que eu sabia ter lido

ela tinha gravado na sua carne $!^{274}$

Neste poema, nota-se uma clara identificação entre os povos angolanos a partir de um olhar à História comum que viveram, sendo um dos principais aspectos desta identidade o passado de exploração e sofrimento a que foram submetidos durante o período do tráfico atlântico de escravos, ainda que o contato e a exploração tenham sido muito diferentes no tempo, no espaço, na intensidade e na forma como se deram.

Além de uma identificação entre os povos angolanos para construir um sentimento de comunhão nacional, os Novos Intelectuais de Angola também manifestavam uma identificação com os povos negros, tanto africanos quanto americanos. O passado de exploração e o sentimento de esperança na libertação foram enunciados por Viriato da Cruz no poema Mamã Negra:

Tua presença, minha Mãe - drama vivo duma Raça,

Drama de carne e sangue

Que a Vida escreveu com a pena dos séculos!

Pela tua voz

Vozes vindas dos canaviais dos arrozais dos cafezais dos seringais dos

algodoais!...]

Vozes das plantações de Virgínia

dos campos das Carolinas

Alabama

Cuba

Brasil... (...)

Pelo teu dorso

Rebrilhantes dorsos aos sóis mais fortes do mundo!

Rebrilhantes dorsos, fecundando com sangue, com suor amaciando as mais ricas terras do mundo!]

Rebrilhantes dorsos (ai, a cor desses dorsos...)

Rebrilhantes dorsos torcidos no "tronco", pendentes da forca,caídos por Lynch!

Rebrilhantes dorsos (Ah, como brilham esses dorsos!)

ressuscitados em Zumbi, em Toussaint alevantados!

Rebrilhantes dorsos...

brilhem, brilhem, batedores de jazz

rebentem, rebentem, grilhetas da Alma

evade-te, ó Alma, nas asas da Música!

...do brilho do Sol, do Sol fecundo

274 OLIVEIRA, Mario António Fernandes de. "Poema”. Revista Mensagem - a voz dos Naturais de Angola. Editado pelo Departamento Cultural na Associação dos Naturais de Angola, números 2-4, ano II, 1952. p. 4. 
imortal

e belo...

Pelo teu regaço, minha Mãe,

Outras gentes embaladas

à voz da ternura ninadas

do teu leite alimentadas

de bondade e poesia

de música ritmo e graça...

santos poetas e sábios... (...)

Pelos teus olhos, minha Mãe

Vejo oceanos de dor

Claridades de sol-posto, paisagens

Roxas paisagens

Dramas de Cam e Jafé...

Mas vejo (Oh! se vejo!...)

mas vejo também que a luz roubada aos teus olhos, ora esplende

demoniacamente tentadora - como a Certeza...

cintilantemente firme - como a Esperança...

em nós outros, teus filhos,

gerando, formando, anunciando -

o dia da humanidade

O DIA DA HUMANIDADE! ${ }^{275}$

Como pode ser percebido no poema destacado acima, Viriato da Cruz e boa parte dos Novos Intelectuais de Angola entendiam que a história dos povos negros, tanto na África quanto na América, os unia, criando uma identificação entre eles. ${ }^{276}$ Sendo assim, era papel fundamental dos intelectuais levar adiante a construção de uma cultura negra africana.

Viriato da Cruz, no influente artigo Das responsabilidades do intelectual negro, ainda destacava a necessidade de afirmação dos negros como Homens após um longuíssimo período de exploração colonial, quando os povos africanos foram considerados inferiores. Neste mesmo documento, Viriato da Cruz defendia que seria impossível que os intelectuais negros levassem a cabo seus objetivos sem ter a posse do seu Estado, claramente aliando suas ideias

\footnotetext{
275 CRUZ, Viriato. "Mamã Negra". Revista Mensagem - a voz dos naturais de Angola. Edição do Departamento Cultural da Associação dos Naturais de Angola, número 1, ano I. 1951, p. 4.

276 Vale destacar aqui a consonância de ideais entre artistas ligados ao Movimento dos Novos Intelectuais de Angola e o pan-africanismo, principalmente no que diz respeito à identificação entre os povos africanos e todos os povos que viviam em situação de diáspora, em especial no continente americano.
} 
culturais a uma contundente crítica ao colonialismo português. Alinhavava-se, portanto, as manifestações culturais dos Novos Intelectuais Angolanos às questões políticas. ${ }^{277}$

Ao mesmo tempo em que se denunciava o colonialismo como uma questão a ser superada caso realmente se quisesse encontrar um caminho para a valorização dos povos angolanos e suas culturas, o movimento dos Novos Intelectuais de Angola apontava para um futuro de esperança ao olhar para o passado e projetar o futuro do país. ${ }^{278}$ Desta forma, o voluntarismo dos Novos Intelectuais de Angola logo se transformaria em uma ação política coordenada através de movimentos de libertação nacional que propunham a luta armada contra o colonialismo português.

\section{Conclusão}

Qualquer estudo que se debruce sobre a cultura angolana se depara como uma imensa multiplicidade de matrizes culturais. Sabendo disso, é possível notar que, tal como vimos na parte inicial deste artigo, a identidade nacional é necessariamente redutora, já que não é possível unir todas as influências culturais em somente uma construção identitária. Sendo assim, é possível compreender que a definição identitária de uma nação é feita sempre a partir de uma seleção das matrizes culturais que os construtores deste discurso identitário consideram legitimamente representantes da nação. Sabendo disso, é importante ressaltar que, mesmo redutora e seletiva, a identidade nacional que o Movimento dos Novos Intelectuais de Angola tentou forjar sempre esteve conectada aos valores culturais e políticos que esta geração de intelectuais defendeu, tais como o interesse por algumas línguas nativas, pelo folclore e pelas tradições, e o interesse em ressaltar uma resistência cultural e política contra o colonialismo. Contudo, o objetivo de unir todos os povos angolanos em torno de somente uma identidade nacional ainda esbarraria em diversos problemas identitários que se manifestariam durante a luta de libertação nacional iniciada em 1961. Apesar disso, a

\footnotetext{
277 CRUZ, Viriato. "Das responsabilidades do intelectual negro". In: ROCHA; SOARES; FERNANDES (orgs). op. cit., p. 373. Este documento é de grande importância na trajetória de Viriato da Cruz, uma vez que a articulação dos temas culturais com problemas políticos angolanos foi cada vez mais divulgada pelo intelectual. Em pouco tempo, Viriato da Cruz passaria a se dedicar cada vez mais à luta política contra o colonialismo, deixando em segundo plano a sua produção artística.

278 É significativa a mensagem de esperança em um futuro melhor no poema de Leston Martins intitulado "Canto de Amor e Esperança" publicado pela Mensagem - a voz dos naturais de Angola. Edição do Departamento Cultural da Associação dos Naturais de Angola, Luanda, julho de 1951, número 1, p. 11.
} 
contribuição dada pela geração dos Novos Intelectuais de Angola à construção de um discurso identitário foi fundamental para o surgimento da nação que se intentava construir.

\section{Referências Bibliográficas}

ANDERSON, Benedict. Comunidades imaginadas: reflexões sobre a origem e a difusão do nacionalismo; tradução Denise Bottman. - São Paulo: Companhia das Letras, 2008.

BHABHA, Homi K. O local da cultura. Belo Horizonte: Editora da UFMG, 1998.

BOSSLET, Juliana Cordeiro Farias. A Cidade e a Guerra: relações de poder e subversão em São Paulo de Assunção de Luanda. Dissertação de mestrado apresentada ao Programa de PósGraduação em História Social da Universidade Federal Fluminense. Niterói, 2014.

CASTELO, Cláudia. A Casa dos Estudantes do Império: lugar de memória anticolonial. In Memories of Colonialism: rememberance, resistance and transference in anti-colonial african narratives. Disponível em https://repositorio.iscte-iul.pt/handle/10071/2244.

CHAVES, Rita. A Formação do Romance Angolano: entre intenções e gestos. São Paulo: FBLP, Via Atlântica, 1999.

CHAVES, Rita. Angola e Moçambique: experiência colonial e territórios literários. Cotia, SP: Ateliê Editorial, 2005.

CHAVES, Rita. MACÊDO, Tania (orgs.). Marcas da Diferença: as literaturas africanas de língua portuguesa. São Paulo: Alameda, 2006.

COOPER, Frederick. Conflito e Conexão: repensando a história colonial da África. Porto Alegre: Anos 90. V. 15, no 27. 2008. (Disponível em http://www.seer.ufrgs.br/anos90/article/viewFile/6739/4041)

DUARA, Prasenjit. Historicizing national Identity, or who imagines what and when. In: Eleyand Suny, Becoming National, Oxford, Oxford University Press, 1996, p. 150-177.

HOBSBAWM, Eric. Nações e nacionalismos desde 1740: programa, mito e realidade. Rio de Janeiro: Nova Fronteira, 2011.

LABAN, Michel. Angola: encontro com escritores, volume 1. Porto, Fundação Eng. António de Almeida, 1991.

MATA, Inocência. PADILHA, Laura (orgs). Mário Pinto de Andrade - um intelectual na política. Lisboa: Edições Colibri, 1997. 
MCQUEEN, Norrie. A descolonização da África Portuguesa: a revolução metropolitana e a dissolução do Império. Mem Martins: Inquérito, 1998.

PEPETELA. Algumas questões sobre literatura angolana. Disponível em http://www.ueangola.com/criticas-e-ensaios/item/122-algumas-quest\%C3\%B5es-sobre-aliteratura-angolana. Acesso em 26 de maio de 2015.

PIMENTA, Fernando Manuel Tavares Martins. Brancos de Angola: autonomismo e nacionalismo (1900-1961). Coimbra: Edições Minerva, 2005.

PIRES LARANJEIRA. Literaturas africanas de expressão portuguesa. Lisboa: Universidade Aberta, 1995.

POLLAK, Michel. Memória, Esquecimento, Silêncio. In: Estudos Históricos, Rio de Janeiro, volume 2, número 3, 1989. p. 3-15

ROCHA, Edmundo, SOARES, Francisco, FERNANDES, Moisés (orgs). Viriato da Cruz: o homem e o mito - Porto Amboim (Angola), 1928 - Beijing (China) 1973. Luanda, Caxinde, 2008.

SAID, Edward. Cultura e Imperialismo. São Paulo: Companhia das Letras, 1995.

SERRANO, Carlos. Angola: a Geração dos 50, os jovens intelectuais e a raiz das coisas. Disponível no site da União dos Escritores Angolanos: http://www.ueangola.com/criticas-eensaios/item/157-angola-a-gera\%C3\%A7\%C3\%A3o-de-50--os-jovens-intelectuais-e-a-raizdas-coisas. Acesso em 22 de julho de 2015.

THOMPSON, Edward. Costumes em Comum. São Paulo: Companhia das Letras, 1998.

\section{Fontes}

ASSIS Jr. António. O Segredo da Morta (romance de costumes angolenses). 2a․ Edição. Lisboa, Edições 70, 1979.

BOLETIM - Casa dos Estudantes do Império, Ano 1, número 6.

BOLETIM - Casa dos Estudantes do Império, ano II, número 8.

SOROMENHO. Terra Morta. Luanda, União dos Escritores Angolanos, 1985.

SOROMENHO. Viragem. São Paulo, Arquimedes, 1967.

FERREIRA, José Silva Maia. Espontaneidades da minha terra - às senhoras angolanas. Lisboa: Imprensa Nacional/ Casa da Moeda, 2002. Coleção Escritores dos Países de Língua Portuguesa, volume 30 . 
JACINTO, António. O Grande Desafio. Disponível em http://www.portalsaofrancisco.com.br/alfa/antonio-jacinto/poesias.php. Acessado em 16 de junho de 2015.

MENSAGEM. Casa dos Estudantes do Império, Ano III, números 5 e 6.

MENSAGEM, ano III, números 3 e 4, Boletim da Casa dos Estudantes do Império, Lisboa, 1960. MENSAGEM - Boletim da Casa dos Estudantes do Império, ano III, número III MENSAGEM- Boletim da Casa dos Estudantes do Império. Ano III, número I. NETO, Agostinho. Renúncia impossível. 1949. Disponível em http://www.agostinhoneto.org/index.php?option=com content\&view=article\&id=537:arenuncia impossivel\&catid=65:renuncia-impossível\&ltemid $=233$. Acesso em 2 de junho de 2015.

REVISTA MENSAGEM - a voz dos naturais de Angola. Luanda: ANANGOLA, Ano 1, julho de $1951, \mathrm{n}$ ⒈

REVISTA MENSAGEM - a voz dos Naturais de Angola. Editado pelo Departamento Cultural na Associação dos Naturais de Angola, números 2-4, ano II, 1952. 